\title{
Pensar las coaliciones en la Argentina contemporánea
}

\section{Think coalitions in contemporary Argentine \\ César Tcach}

César Tcach es profesor en la Universidad Nacional de Córdoba e investigador del CONICET, Argentina

E-mail: cesartcach@gmail.com

\section{resumen}

Este artículo analiza el fracaso de los procesos de conversión de las coaliciones electorales en coaliciones de gobierno, y la difícil institucionalización de las coaliciones en Argentina, desde una perspectiva de estudio interesada en destacar la articulación entre factores históricos de larga duración y transformaciones políticas recientes. Desde este ángulo de preocupaciones, se sostiene que las coaliciones fueron más un instrumento de construcción de hegemonía en clave de gobierno de "unidad nacional" que un sistema de pactos inspirado en el principio del poder compartido.

\section{summary}

This article analyzes the failure of the processes of conversion of the electoral coalitions in coalitions of government, and the difficult institutionalization of the coalitions in Argentina, from a perspective of study interested in emphasizing the joint between historical factors of long duration and political recent transformations. From this angle of worries, is held that the coalitions were more an instrument of construction of hegemony in key of government of "national unit" that a system of agreements inspired by the beginning of the shared power.

\section{palabras clave}

coaliciones políticas / corporaciones / hegemonía / ingeniería de cooptación

\section{keywords}

political coalitions / corporations / hegemony / cooptation of engineering 


\section{Introducción}

En los inicios de la transición democrática argentina, en los diversos centros académicos y de investigación social-CLACSO, CEDES, CISEA, entre otros-se discutía mucho acerca de las relaciones entre partidos y corporaciones, la fortaleza o debilidad del sistema de partidos, las herencias del pasado, la inflación y los peligros que asechaban la consolidación del proceso abierto en 1983. Empero, el tema de las coaliciones aparecía como un factor que distaba de ocupar un lugar central en la agenda de la discusión politológica. Esta situación comenzó a variar a partir de la exitosa irrupción del Frente Grande en las elecciones constituyentes de 1994 y particularmente del FREPASO en los comicios generales del año siguiente, cuando alcanzó un impactante $29,5 \%$ de los sufragios.

A tenor de ese contexto histórico, entre 1997-1999, una parte de la comunidad politológica argentina acarició la idea de la posibilidad de constitución de un sistema de partidos de pluralismo moderado, es decir, con dos coaliciones, una de centro derecha y otra de centro izquierda que se sucediesen alternativamente en el ejercicio del poder. El politólogo mexicano Leonardo Valdés Zurita, en un libro editado por el Instituto Federal Electoral puso a la Argentina como ejemplo de pluralismo moderado (Valdés, 2001: 25-28); Antonio Camou hacía referencia al pasaje del bipartidismo al bialiancismo (Camou, 2000: 11-30), y Julio Burdman, entre otros, estudiaba su viabilidad en relación a los sistemas de ballotage (Burdman, 1997: 447).

La estabilidad política democrática sustentada en una dinámica bipolar se reveló pronto como una ilusión. Aún antes de la crisis de 2001, la vertiginosa erosión de la Alianza UCR-FREPASO que había llevado a la presidencia a Fernando de la Rúa, puso al desnudo los límites del coalicionismo argentino. Dos años después de aquella crisis, en el primer libro de política comparada centrado en la problemática de las relaciones entre presidencialismo y coaliciones en América latina (Lanzaro, 2003), emergían con claridad las dificultades de las coaliciones en Argentina para proveer sólidas bases a la capacidad de gobierno (Novaro, 2003: 89). La "Alianza", pues, careció de una instancia política desde la cual se tomaran las decisiones clave de la gestión y que hiciese posible "un proceso de toma de decisiones con algún grado de institucionalización” (Ollier, 2001: 11).

Lo expuesto, empero, no oscurece la génesis de nuevas y sucesivas coaliciones. En nuestros días es fácil constatar que dada la fragmentación del formato partidario y la territorialización del voto (Calvo, 2005: 153-160), las coaliciones y los gobiernos de coalición constituyen un dato ineludible del futuro político argentino. Entonces, el problema que irrumpe a flor de piel es el de la inestabilidad de las coaliciones como un dato estable de la política argentina. Esta cuestión es indisociable no solo de factores históricos de larga duración -que se analizan en este texto-sino también de la transformación en curso de los partidos políticos, cuyos sustentos sociales y función representativa son erosionadas en consonancia con la emergencia de "líderes de popularidad" que carecen del "control de instancias dirigentes a las que tengan que rendir cuenta de sus actos" (Cheresky, 2007: 13-16). 


\section{El diagnóstico}

La noción de coaliciones tiene un carácter polisémico. En clave sociológica remite a convergencias, fusiones o frentes entre actores sociales (Di Tella, 1999: 28). Así por ejemplo, al analizarse el Partido Demócrata norteamericano en la época de Franklin Roosevelt, se señala la confluencia de obreros, intelectuales y clase media baja del norte de EE.UU. con una clase alta racista y autoritaria que conducía a los "blancos pobres" del sur de ese país (Di Tella, 2004: 17). En una mirada más politológica, en cambio, la noción de coaliciones tiene como núcleo duro el principio del poder compartido entre partidos y grupos políticos a partir de un sistema de pactos y reglas internas que regulan los juegos de poder, definen las pautas de negociación y determinan instancias de resolución de conflictos. En esta investigación, se considera productivo el empleo de la noción de coaliciones en ambos sentidos, dado que a efectos interpretativos, se trata de dimensiones de análisis complementarias.

La ilusión politológica de 1997-98, que miraba con optimismo la posibilidad del afianzamiento de una dinámica bipolar de carácter centrípeto, no era ajena al fuerte potencial coalicional que se advertía en la constitución de las principales identidades políticas argentinas.

En las primeras décadas del siglo XX, como es sabido, la Unión Cívica Radical se constituyó a partir de una confluencia heterogénea: sectores populares de los principales centros urbanos, núcleos patricios de Buenos Aires, Córdoba y Salta, colonos del centroeste santafecino y de la pampa gringa cordobesa, entre otros, en el marco de una sociedad "abierta y móvil" (Romero, 2004: 32-33). Se ha llegado a sostener, incluso, que el partido radical fue sostenido por vastos sectores "sin preeminencia de ninguno de ellos" (Lupu-Stokes, 2009: 517).

También el peronismo se constituyó inicialmente de modo coalicional. Como en su momento sostuvimos con Darío Macor, en sus orígenes el peronismo ya no puede ser percibido como un movimiento que tuvo en la clase obrera su "columna vertebral" y en la oligarquía su "enemigo natural", sino que, en sus niveles de dirección agrupó, sobre todo en el interior del país, a sectores de poder en las provincias: viejos caudillos departamentales conservadores y un sector de la "aristocracia" de toga en Córdoba, una parte de la oligarquía azucarera salteña (no olvidemos que el primer gobernador peronista de Salta fue el terrateniente Lucio Cornejo, dueño del ingenio San Isidro), notables y ricos (con dinero pero sin tradición) en los territorios nacionales del sur del país (Macor-Tcach, 2003).

A esta tradición, que podemos llamar "coalicional" tampoco fue ajeno el conservadorismo. La Federación Nacional Democrática constituida a principios de la década del treinta y el propio partido demócrata nacional fueron el resultado de coaliciones entre grupos oligárquicos provinciales, o al menos, de notables provinciales. Lo mismo ocurrió en la década del sesenta, cuando la derecha formó la Federación de Partidos de Centro frente al gobierno radical de Arturo Illia (TcachRodriguez, 2006). También el desarrollismo argentino, el frondicismo, tuvo en sus orígenes un relevante componente coalicional. 
Entonces, se puede formular aquí una primera constatación, la existencia de una cultura coalicional en la matriz de las principales identidades políticas, como condición de posibilidad para la formación de alianzas políticas. Sin embargo, esta valoración contrasta con la inestabilidad de las coaliciones en Argentina. No me refiero solamente a los estridentes fracasos de las coaliciones que protagonizaron Fernando de la Rúa y Carlos Chacho Alvarez o diez años más tarde Cristina Kirchner y Cleto Cobos. Porque esa inestabilidad se reproduce en niveles provinciales, municipales y comunales. Se producen continuamente rupturas de coaliciones a nivel macro y a nivel micro. Su común denominador reside en las dificultades que enfrentan los procesos de conversión de las coaliciones electorales en coaliciones de gobierno.

Una explicación de tipo insitucionalista podría señalar que un sistema presidencialista con parlamento devaluado y centralización de recursos en el Estado Nacional, genera un conjunto de incentivos selectivos que opera en detrimento de la estabilidad coalicional. Sin embargo sabemos, incluso por las experiencias recientes de países vecinos como Chile y Uruguay, que el presidencialismo no es incompatible con la formación de coaliciones estables y duraderas (Chasquetti, 2008 y 2003).

Me inclino a considerar también otros factores que remiten a las características históricas de la cultura política coalicional en Argentina, la existencia de un arco de preferencias coalicional alternativo al de los partidos, la matriz movimientista y el carácter superestructural de las alianzas.

\section{Entre el movimientismo y la ingeniería de cooptación}

Argentina combina una fuerte tradición de coaliciones o alianzas con una cultura política coalicional de baja intensidad. Esto puede parecer una contradicción, fuerte tradición coalicionista y cultura política coalicional de baja intensidad. Sin embargo, desde mi perspectiva de análisis, la intensidad de la cultura coalicional se debe valorar y evaluar en función del conjunto de representaciones y prácticas que los actores políticos desarrollan a efectos de favorecer la legitimidad, estabilidad y consolidación de las coaliciones. Entonces, si bien la cultura coalicional es amplia por su extensión entre las principales fuerzas políticas, y por la magnitud del potencial coalicional (no hay barreras clasistas, raciales o confesionales- es un potencial en buena medida catch all), la misma es de baja intensidad porque estuvo anclada históricamente en un modelo originario (Panebianco, 2009) de matriz movimientista, sometido a fuertes tensiones. ¿Cómo se manifestó en los diversos espacios políticos esa cultura coalicional amplia pero de baja intensidad? Pues veamos:

1. En el caso del peronismo, la alianza era una variable dependiente del liderazgo carismático. Por lo tanto, de una dimensión vertical de la política. Con un agravante que dista de ser un dato menor. La relación simbiótica entre liderazgo y Estado. Cabe recordar en los años cincuenta, la composición del Comando Estratégico, de los Comandos Tácticos y de 
los Subcomandos Tácticos. El primero era presidido por el presidente de la nación y se reunía en la Casa Rosada, los segundos eran presididos en cada provincia por el gobernador respectivo y se reunían en la Casa de Gobierno, los terceros eran presididos por los intendentes y se reunían en sede municipal. No ha de extrañar entonces, que tras la muerte de Perón y la larga crisis de sucesión, la alianza se convirtiese en una variable dependiente del Poder Ejecutivo Nacional o de los gobernadores.

Desapareció el liderazgo carismático pero no el verticalismo estatalista y personalista que marcó su origen, condicionando las alianzas en un doble sentido: la asimetría interna dado que los actores están sujetos a un centro o vértice situado en el Estado. Y su carácter coyuntural, meramente instrumental. De allí, la volatilidad de los "compañeros de ruta": no son actores fijos sobredeterminados por afinidades ideológicas.

2. En el caso del partido radical, la idea de alianza -pese a ser la propia UCR una alianza- tuvo varios contrapesos importantes. En primer lugar, la concepción yrigoyenista según la cual el radicalismo era la expresión de la nacionalidad y, al mismo tiempo, su agente constructor-concepción que se nutría también de una fuerte influencia krausista-operó en detrimento de una política de alianzas. El radicalismo era concebido como la expresión totalizadora de la voluntad nacional y democrática de los argentinos. Vinculada a esta concepción se construyó una noción de consenso, no como el fruto de una esforzada negociación entre actores sino como el resultado de la acción honesta de sus dirigentes (Smulovitz, 1993). Esa forma de hacer política plegaría a su favor al conjunto de la ciudadanía. En el fondo, latía también con fuerza la tentación movimientista, pero - a diferencia del peronismo- no en clave corporativa sino anclada en un partido de ciudadanos.

3. En el caso de los sectores liberal-conservadores, la idea de alianza que ellos practicaron en las décadas del treinta (Federación Nacional Democrática), los sesenta (Federación de Partidos de Centro), los setenta (Alianza Popular Federalista) y los noventa (alianza de la Unión de Centro Democrático con el menemismo) chocó siempre con dos obstáculos formidables: su desinterés por la democracia interna y su fácil seducción por actores corporativos. Estos factores restaron densidad a su propio interés por la fórmula organizativa partido.

A partir de lo expuesto, se puede afirmar que en la clave movimientista que, con diversos matices diferenciales, construyeron sus identidades radicales y peronistas, las alianzas fueron más una fórmula para construir hegemonía que para edificar consensos entre reconocidos como pares en el juego político. Es decir, para las principales fuerzas, la idea de coalición se asocia a la idea de hegemonía y de compañeros de ruta contingentes. En el caso del peronismo supone la existencia 
de una aceitada ingeniería de cooptación cuyas habilidades forman parte de un acervo histórico que le permitió "devorar" (es decir, absorber o reducir a su mínima expresión) a partidos situados a su izquierda o a su derecha (como el partido conservador popular en los setenta o la UCD en la época dorada del menemismo). En el caso de la UCR, el "panradicalismo" o las alianzas con partidos fuertes en el plano subnacional (como el Partido Socialista) no implicó necesariamente la desintegración de los aliados. Subyace en cambio, la idea de un "contrato moral" (expresión recurrente en Elisa Carrió, tributaria de la tradición radical), que es más un acuerdo entre iguales honestos que un compromiso entre diferentes. Lo que subyace de común en ambas miradas es una representación de las alianzas de gobierno más cercana a la idea de "gobierno de unidad nacional" que al principio del poder compartido.

\section{La tentación corporativa}

Si la hipótesis planteada en el apartado anterior remite a la tentación hegemónica, la siguiente conduce a la tentación corporativa: alude a la importancia de un arco de preferencias coalicionales alternativo al de los partidos.

El sistema político argentino funcionó históricamente a través de un doble canal de mediación: el corporativo y el partidario. La primacía de la mediación corporativa tuvo contundentes expresiones a lo largo de toda la historia argentina del siglo XX: entre 1900 y 1940 la casi totalidad de los ministros de agricultura y ganadería fueron miembros de la Sociedad Rural (Ansaldi, 1993); algunos partidos operaron en contra del sistema de partidos aliándose con la Acción Coordinadora de Instituciones Empresariales Libres (ACIEL) para derrocar a Illia en 1966 y con la Asociación Permanente de Entidades Gremiales Empresariales (APEGE) para destituir al gobierno peronista en 1976.

Cabe añadir, que estos actores externos al sistema de partidos, establecían y aún hoy tratan de establecer alianzas fácticas dotadas de una fuerte vocación hegemónica. Recuérdese, por ejemplo, el papel de la Fundación Mediterránea durante los años dorados del neoliberalismo menemista; o entre 2008-2009, la mirada acrítica de los partidos políticos opositores hacia la Mesa de Enlace conformada por las principales asociaciones de propietarios agrarios.

En la primera década del siglo XXI, los militares ya no son sujetos de posibles alianzas con oposiciones partidarias semileales o desleales (Linz, 1996). La Iglesia Católica, en cambio, continúa seduciendo con su respaldo a determinados liderazgos y opciones partidarias, sobre todo cuando se tratan temas vinculados a educación y salud reproductiva. Pero el papel central lo protagonizan aquellos actores privados vinculados al mercado financiero con capacidad para definir en determinadas coyunturas cierta "disciplina de mercado" (Iazzetta, 2007: 158159). Su presencia en el escenario político dista de ser neutra en la definición de las políticas de alianzas formuladas por los líderes partidarios.

Lo anteriormente expuesto, supone la configuración de un espacio de alianzas alternativo al de la cooperación interpartidaria. Es decir, implica afirmar la existencia de un menú de opciones más amplio que el ofrecido por el sistema 
de partidos. Implica un abanico alternativo de alianzas que eventualmente puede ser más rentable y eficaz que el que se puede generar a partir de la cooperación interpartidaria. Por consiguiente, el cálculo racional indica a los actores que la configuración de un bloque de poder, sea de gobierno o de oposición, debe dejar a sus líderes un importante margen de autonomía decisional para negociar con esos actores políticos implícitos.

La incidencia del arco de preferencias coalicionales con actores externos al sistema de partidos adquiere una mayor relevancia, en consonancia con la pérdida de intensidad de las identidades colectivas partidarias y la erosión del rol de los militantes en sus organizaciones. Asimismo, la asimetría interna que pueden contener esas alianzas entre líderes partidarios y actores privados o corporativos se acrecienta en consonancia con la fragmentación del formato partidario (Quiroga, 2010a: 148, 162). Por otra parte, la débil disciplina de voto en los bloques parlamentarios resta densidad al compromiso de los legisladores individuales con sus propios partidos y/o coaliciones, circunstancia que eventualmente puede facilitar la tarea corporativa de captura de sus votos (Mainwaring-Soberg Shugart, 2002: 258).

\section{La difícil institucionalización de las coaliciones}

A diferencia de Chile y Uruguay, en Argentina las coaliciones combinan un fuerte carácter superestructural con un débil grado de institucionalización. Las coaliciones no son el fruto de una construcción social que permita concebirlas en la dimensión horizontal de la política. En este sentido, el asociacionismo político es débil. Lejos de ser un producto de la política como ámbito de deliberación, las alianzas son más bien, el resultado de la política como espacio de decisión de sus líderes. En este sentido, las coaliciones expresan menos clivajes sociales que elecciones de líneas divisorias definidas por los dirigentes en función de sondeos y encuestas de opinión. Por consiguiente, parece tener más peso el beneficio mediático inmediato que el beneficio institucional en el mediano y largo plazo. Ello a su vez, puede tener como consecuencia una disociación entre tres tipos de beneficios: el obtenido por el líder, el beneficio partidario y el beneficio coalicional. Estas tensiones se resuelven -en la práctica de los políticos argentinos-en una ecuación personalista, donde tiende a primar siempre el primero. Es por eso, que una práctica política coalicional sujeta a normas que restringiesen la libertad de acción de las partes, y sobre todo, de sus líderes máximos, puede ser percibida como una potencial hipoteca política.

En esa lógica personalista, el carácter superestructural se vincula a la primacía del cortoplacismo. Este cortoplacismo se asocia asimismo, a la percepción del éxito inmediato como el capital más preciado y sus efectos sobre la democracia interna, -en los partidos y con mayor razón en las coaliciones-son desvastadores. Se ha sostenido que el éxito electoral de una coalición predispone a sus miembros al mantenimiento del pacto. El caso de Convergencia y Unión, en Cataluña, ha sido presentado como una prueba al respecto (Reniu, 2002). Sin embargo, la impronta personalista de la cultura política argentina parece relativizar la universalidad de 
la tesis. El rendimiento electoral dista de ser la variable independiente que permita explicar el éxito o el fracaso de una coalición. En las coaliciones realmente existentes -al menos en la gran mayoría de ellas- el escaso grado de correspondencia entre normas y prácticas, abre un horizonte acechado de incertidumbres tanto en el triunfo como en la derrota. Así, por ejemplo, la renuencia a realizar elecciones internas puede ampararse en argumentos simétricamente opuestos: no practicarlas porque se viene de una victoria y el espacio está viviendo un momento ascendente o bien porque está en un momento de crisis o debilitamiento y su realización contribuiría a potenciar las divisiones.

Los múltiples caminos que se abren tras las coyunturas electorales, son potenciados por la existencia de "juegos anidados", es decir, por la superposición de arenas políticas correspondientes a diversos planos: municipal, provincial y nacional. Las eventuales ligas de gobernadores y redes de intendentes en lugares como el conurbano bonaerense, acentúan los problemas de institucionalización. Este fenómeno, estrechamente vinculado a la territorialización de la política (CalvoEscolar, 2005), ancla su potencialidad no sólo en la diversificación del sistema de partidos sino también en la descentralización del poder partidario, y el ya nombrado predominio de mediáticos "liderazgos de popularidad".

\section{Conclusiones}

E. Carrió: el único límite a la formación de alianzas es la corrupción.

M. Bonelli: entonces no hay límite político o ideológico.

E. Carrió: no, porque se roba por derecha y por izquierda. (programa televisivo A Dos Voces, 22-9-2010)

La primacía de lo superestrucutural en las modalidades de hacer política y establecer compromisos, el peso de actores externos - privados o corporativos- el personalismo y la matriz movimientista constituyen la matriz político cultural del coalicionismo argentino. Es por eso que las coaliciones argentinas, lejos de sustentarse en el principio del poder compartido, son construcciones marcadas por la tentación hegemónica, la ingeniería de cooptación y la permeabilidad a los intereses corporativos. Su proa visionaria apunta más a la idea de gobierno de unidad nacional con liderazgo fuerte que a la regulación de compromisos basados en la distribución de poder.

Entonces, la débil institucionalización no es la causa de la debilidad de las coaliciones sino su correlato, es decir, producto y manifestación de un conjunto de determinaciones ancladas en las matrices de la política partidaria en Argentina. En su cultura coalicional, -el conjunto de representaciones de los actores políticos acerca de las coaliciones entre partidos- las alianzas no son fórmulas para construir consensos y viabilizar políticas públicas, sino una suerte de ingeniería de cooptación al servicio de una vocación hegemónica.

Este fenómeno se expresa también en el terreno de los movimientos sociales. Su desarrollo como forma ordinaria de participación política hace impensable la cons- 
titución de coaliciones y la elaboración de políticas públicas que, al menos, no tengan presente su jerarquía de prioridades (Neveu, 2002: 62-64). La recepción de sus reivindicaciones, y más aún la inclusión de ese tipo de actores extrapartidarios empero, tiende a ser procesada en clave de manipulación política.

Dos fenómenos convergentes coadyuvan a agravar la inestabilidad potencial de las coaliciones. La progresiva conversión de los espacios políticos en partidos de funcionarios y la certeza de vivir en una situación de emergencia permanente (Quiroga, 2005). Ambas tendencias tienden a legitimar modalidades decisionistas de hacer política. Asimismo, el presidencialismo y la centralización de recursos en el Estado nacional favorecen la orientación fundacional de los líderes. Con frecuencia huérfanos de bases sociales leales y aparatos partidarios consistentes, experimentan la tensión entre el imperativo de generar altas expectativas -básicamente a través de los medios de comunicación- para reproducir su legitimidad en el espacio público y la posibilidad de saldarlas (Cheresky, 2007).

En el caso de las fuerzas opositoras, la deriva de estas circunstancias es la elaboración de un relato re-fundacional en clave ética catch all como el incluido en el epígrafe que da inicio a estas reflexiones. Por cierto, la tendencia hacia el centro se constata en la mayor parte de las democracias occidentales, pero una cosa es transitar esa convergencia desde la derecha y otra desde los valores de la cultura de izquierda (Bobbio, 2004). Es decir, desde valores colectivos como libertad política, igualdad social, igualdad de género y diversidad (Quiroga, 2010b).

En la Argentina que atraviesa la frontera del bicentenario, gobierno y sectores relevantes de la oposición, parecen sucumbir a la fascinación de pensar las coaliciones en términos personalistas, cortoplacistas, y en el más exitoso de los casos, en clave de gobierno de unidad nacional y no del principio del poder compartido.

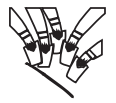

\section{Bibliografía}

W. ANSALDI (1993), "Mediaciones políticas y construcción de la democracia argentina" en Revista Estudios $\mathrm{N}^{\circ} 3$, Centro de Estudios Avanzados de la Universidad Nacional de Córdoba.

N. BOBBIO (2004), Derecha e izquierda, Buenos Aires, Ed. Punto de Lectura.

J. BURDMAN (1997), "Estrategias de ballotage y sistema de partidos (si 1999 fuera hoy)", en Desarrollo Económico, Buenos Aires, vol. 37, № 147.

E. CALVO (2005), "Argentina, elecciones legislativas 2005: consolidación institucional del kirchnerismo y territorialización del voto", en Revista de Ciencia Política, Pontificia Universidad Católica de Chile, vol. 25, $\mathrm{N}^{\circ} 2$.

E. CALVO-M. ESCOLAR (2005), La nueva política de partidos en la Argentina, Buenos Aires, Prometeo.

A. CAMOU (2000), "Del bipartidismo al bialiancismo? Elecciones y política en la Argentina posmenemista”, en Perfiles Latinoamericanos, FLACSO-México, $\mathrm{N}^{\circ} 16$.

(2008), “¿Más allá del bipartidismo? El peronismo kirchnerista como problema y solución en la Argentina actual”, en Stockholm Review of Latin American Studies, Estocolmo, Suecia, № 3.

D. CHASQUETTI (2003), "Democracia, multipartidismo y coaliciones en América Latina: evaluando la difícil combinación", en J. LANZARO (comp.), Tipos de presidencialismo y coaliciones políticas en América Latina, Buenos Aires, CLACSO. 
(2008), Democracia, presidencialismo y partidos politicos en América Latina: evaluando la dificil combinación, Montevideo, Cauce.

I. CHERESKY (2007), La política después de los partidos, Buenos Aires, Prometeo.

T. DI TELLA (1999), Actores y coaliciones. Elementos para una teoría de la acción política, Buenos Aires, Instituto Torcuato Di Tella-PNUD.

Intelectual.

O. IAZZETTA (2007), Democracias en busca de Estado. Ensayos sobre América Latina, Rosario, HomoSapiens.

J. LANZARO (comp.) (2003), Tipos de presidencialismo y coaliciones políticas en América Latina, Buenos Aires, CLACSO.

N. LUPU-S. STOKES (2009), "Las bases sociales de los partidos políticos en Argentina, 1912-2003", en Desarrollo Económico, Buenos Aires, vol. 48, № 192.

J. LINZ (1996), La quiebra de las democracias, Madrid, Alianza Editorial.

D. MACOR-C. TCACH (2003), La invención del peronismo en el interior del país, Santa Fe, Universidad Nacional del Litoral.

S. MAINWARING-M. SOBERG SHUGART (2002), Presidencialismo y sistema de partidos en América Latina, Buenos Aires, Paidós.

E. NEVEU (2002), Sociología de los movimientos sociales, Barcelona, Ed. Hacer.

M. NOVARO (2003), "Presidentes, equilibrios institucionales y coaliciones de gobierno en Argentina (1989-2000)", en J. LANZARO (comp.), Tipos de presidencialismo y coaliciones políticas en América Latina, Buenos Aires, CLACSO.

M. M. OLLIER (2001), Las coaliciones políticas en la Argentina. El caso de la Alianza, Buenos Aires, Fondo de Cultura Económica.

A. PANEBIANCO (2009), Modelos de partido, Madrid, Alianza Editorial.

H. QUIROGA (2005), La Argentina en emergencia permanente, Buenos Aires, Edhasa.

- (2010a), La República desolada. Los cambios políticos de la Argentina (2001-2009),

Buenos Aires, Edhasa.

(2010b), “Introducción: ¿De qué hablamos cuando hablamos de izquierda hoy?”, en Temas y Debates, Rosario, $\mathrm{N}^{\circ} 20$.

J. M. RENIU (2002), La formación de gobiernos minoritarios en España 1977-1996, Madrid, Centro de Investigaciones Sociológicas.

L. A. ROMERO (2004), Sociedad democrática y política democrática en la Argentina del siglo XX, Buenos Aires, Universidad Nacional de Quilmes.

C. SMULOVITZ (1993), "La eficacia como crítica y utopía. Notas sobre la caída de Illia”, en Desarrollo Económico, Buenos Aires, vol. 33, $\mathrm{N}^{\circ} 131$.

C. TCACH-C. RODRIGUEZ (2006), Arturo Illia: un sueño breve. El rol del peronismo y los Estados Unidos en el golpe militar de 1966, Buenos Aires, Edhasa.

L. VALDES (2001), Sistemas electorales y de partidos, México D.F., Instituto Federal Electoral.

Recibido: 04/03/11. Aceptado: 29/03/11.

César Tcach, "Pensar las coaliciones en la Argentina contemporánea". Revista Temas y Debates. ISSN 1666-0714, año 15, número 21, agosto 2011, pp 43-52. 